\title{
Heat transfer during impact
}

\author{
F. BEN-AMMAR, M. KAVIANY and J. R. BARBER \\ Department of Mechanical Engineering and Applied Mechanics, The University of Michigan, \\ Ann Arbor, MI 48109-2125, U.S.A.
}

(Received 4 February 1991 and in final form 14 May 1991)

\begin{abstract}
The amount of heat transferred by conduction during the impact of a spherical particle with a surface depends on the thermophysical and mechanical properties of the two colliding media. Other factors, such as the surface properties (e.g. roughness, contamination, stress state, radius of curvature) and the velocity and direction of the impact, also influence the heat transfer. The available theoretical treatment of the heat transfer is based on the Hertzian theory of elastic contact, where the two colliding media are treated as two elastic half-spaces. In this study experiments are performed to measure the amount of heat transfer during impact of metallic spherical particles with small metallic collectors embedded in low thermal conductivity substrates. Convective heat transfer has been eliminated by performing the experiment in a vacuum chamber. However, radiative heat transfer is present and an effort has been made to minimize it by using highly reflective surfaces. The experimental results show that the measured heat transferred per impact is higher than that predicted by the Hertzian theory of elastic impact. The plastic deformation induced in the collector due to the relatively high velocity of impact causes an increase in the contact area and the impact duration. We analyze the heat transfer during plastic impact and discuss the role of other non-ideal conditions such as the flexibility of the support and the obliqueness of the impact.
\end{abstract}

\section{INTRODUCTION}

SUSPENDED particles in a fluidized bed exchange heat by conduction when they collide with a surface. This heat transfer occurs through the common interface of the particle and the surface (during the collision time) and contributes to the total heat transfer between the bed and the surface. A theoretical analysis by Sun and Chen [1] gives an estimate of the heat transfer during the impact of two elastic particles. The analysis is based on the assumptions that the impact is perfectly elastic, colinear with no spin, the surfaces are smooth and make perfect thermal contact, and that the impact is quasi-static such that the Hertzian theory of elastic impact is valid. In practice the velocities of impact are usually large enough to produce normal stresses larger than the yield stress of the softer material. The impact will then be plastic during the engagement period (contact area increasing with time) and elastic during the rebound period (contact area decreasing with time). As will be discussed, our experiments show that the measured heat transferred is larger than that predicted by the simple theory of elastic impact. This difference is principally attributable to the plastic deformation.

The problem of the elasto-plastic indentation of a half-space by a hard ball has been investigated by various authors [2-5]. These studies are mainly concerned with the size of the permanent plastic indentation, and are generally numerical so that no general solution is available. Tabor [6] performed experiments on the plastic indentation of metals under both dynamic and static loading. Oblique impact of particles has been examined [7, 8], where the erosion of the surface and crater formation was investigated for relatively high velocities of impact. Good agreement was found between the experiments and the predictions. This is because in the experiments the high velocities of impact cause the impact to be fully plastic and the contact pressure is nearly constant throughout the impact duration and equal to the hardness of the softer material. Maw et al. [9, 10] developed a numerical solution for the oblique impact of two elastic spheres of similar materials. They showed that the trajectory of the sphere depends on only two dimensionless parameters. Tsai [11] studied the elastodynamic contact stress between an axisymmetric projectile and an elastic half-space. In his solution, waveeffect integral terms were added to the Hertzian contact stresses. The problem of adhesive contact has been investigated by Barber [12], who provided an analytical solution for that phase of complete adhesion during the oblique impact of elastic spheres of similar materials.

\section{EXPERIMENT}

\subsection{Apparatus}

An apparatus has been constructed (Fig. 1) for the purpose of measuring the total amount of heat transferred during the impact of a spherical particle with a surface. Stainless steel (AISI 440C) spherical particles of diameter $4.76 \mathrm{~mm}$ (3/16 in.) are heated in the heat exchanger. A conveyer driven by an electric motor carries the particles through the heater and drops them at a controllable frequency (ranging from 0 to $2 \mathrm{~Hz}$ ). The spin of the particles is minimized by forcing them to a complete stop before their free fall. Due to gravitational accelcration, they acquire a certain velocity before the collision. The particles collide against a flat, circular metallic collector which is at a 


\section{NOMENCLATURE}

$\begin{array}{ll}A & \text { area of contact, } \pi a^{2}\left[\mathrm{~m}^{2}\right] \\ a & \text { radius of area of contact }[\mathrm{m}] \\ B & V_{1} / V_{\gamma} \\ c_{i} & \text { heat capacity, } i=1,2\left[\mathrm{~K} \mathrm{~K}^{-1} \mathrm{~kg}^{-1}\right] \\ E_{i} & \text { Young's modulus, } i=1,2\left[\mathrm{~N} \mathrm{~m}^{-2}\right] \\ F o & \text { Fourier number } \\ f & \text { bombardment rate }[\mathrm{Hz}] \\ k_{i} & \text { thermal conductivity, } i=1,2 \\ & \left.\text { [W } \mathrm{m}^{-1} \mathrm{~K}{ }^{-1}\right] \\ m_{i} & \text { mass, } i=1,2[\mathrm{~kg}] \\ P & \text { normal contact force }[\mathrm{N}] \\ P & \left.\text { contact pressure [N } \mathrm{m}^{2}\right] \\ Q & \text { heat transferred [J] } \\ \dot{Q} & \text { rate of heat transfer }[\mathrm{W}] \\ q & \left.\text { heat flux [W } \mathrm{m}^{-2}\right] \\ R_{i} & \text { radius of curvature, } \\ & i=1, ?[\mathrm{~m}]\end{array}$

RA Rockwell hardness number, scale A

RF Rockwell hardness number, scale $F$

$T_{i} \quad$ temperature, $i=1,2[\mathrm{C}]$

$t$ time [s]

$V_{1} \quad$ velocity of impact [ms ']

$V_{2}$ rebound velocity $\left[\mathrm{m} \mathrm{s}^{-1}\right]$

$V_{y} \quad$ minimum particle velocity to cause yield in the collector [ $\mathrm{m} \mathrm{s}^{-1}$ ]

$Y \quad$ tensile or compressive yield stress $\left[\mathrm{N} \mathrm{m}^{-2}\right]$.

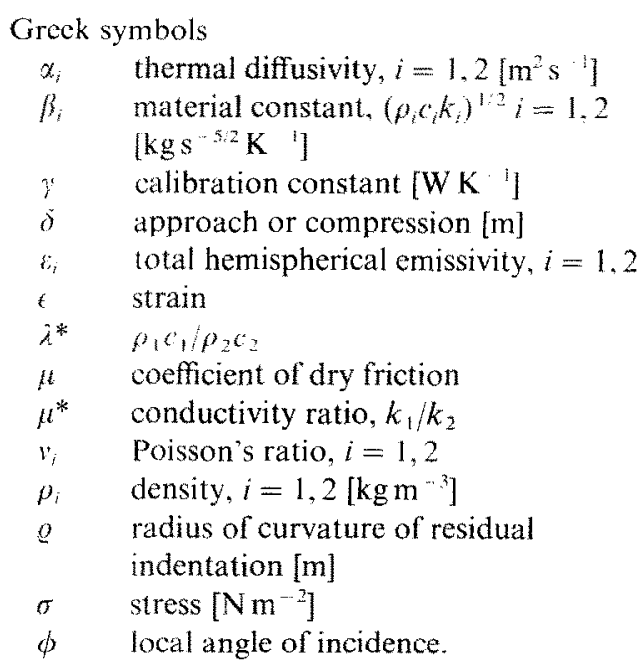

Greck symbols

$\alpha_{i} \quad$ thermal diffusivity, $i=1.2\left[\mathrm{~m}^{2} \mathrm{~s}^{-1}\right]$

$p_{i} \quad$ material constant. $\left(\rho_{i} c_{k}\right)^{1 / 2} i=1.2$ $\left[\mathrm{kgs}^{-5 / 2} \mathrm{~K}{ }^{1}\right]$

$\gamma \quad$ calibration constant [W K ']

$\delta \quad$ approach or compression [m]

$\varepsilon_{i} \quad$ total hemispherical emissivity, $i=1,2$

$\leftarrow$ strain

$\lambda^{*} \rho_{1} \epsilon_{1} \rho_{2} c_{2}$

ik coefficient of dry friction

$\mu^{*} \quad$ conductivity ratio, $k_{1} / k_{2}$

$v_{i} \quad$ Poisson's ratio, $i=1,2$

$\rho_{i} \quad$ density, $i=1,2\left[\mathrm{~kg} \mathrm{~m}^{-3}\right]$

$0 \quad$ radius of curvature of residual indentation $[\mathrm{m}]$

$\sigma \quad$ stress $\left[\mathrm{N} \mathrm{m}^{-3}\right]$

$\phi \quad$ local angle of incidence.

$\begin{array}{cl}\text { Subscripts } \\ 0 & \text { elastic impact } \\ \mathrm{c} & \text { collector } \\ \mathrm{d} & \text { dynamic value } \\ \mathrm{c} & \text { clastic rebound } \\ i & i=1 \text { for particle, } i=2 \text { for collector } \\ \mathrm{p} & \text { plastic engagement } \\ \text { re } & \text { reference collector } \\ \mathrm{R} & \text { mdiation. }\end{array}$

lower temperature. During the impact the particle and the collector exchange heat by conduction through their common interface and by radiation. Due to the rather small amount of heat transferred per impact

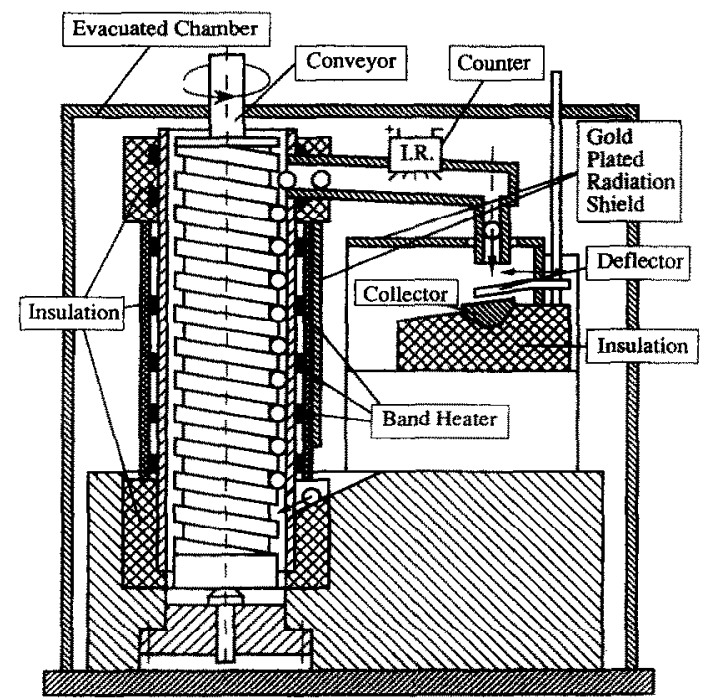

Fic. 1. Experimental apparatus used for the measurement of the conductive heat transfer during impact of spherical particles with a collector. (of the order of $2 \times 10^{-4} \mathrm{~J}$ ), several hundreds of collisions are needed in order to produce a measurable change in the collector temperature. The temperature at various locations in the chamber is measured by chromel-constantin thermocouples. These temperatures are recorded at prescribed time intervals. In order to eliminate all convective heat transfer, the experiment is conducted in an evacuated chamber in which the pressure is kept below $0.02 \mathrm{~atm}$. The radiative heat exchange between the collector and its surroundings is minimized by gold plating the surroundings.

Through a data acquisition and control system the temperatures and the pressure in the chamber are recorded and the temperature of the heat exchanger is controlled. An infrared cell is mounted on the tube through which the particles pass. The cell gives an electric signal every time a particle passes. A counter registers the frequency of these signals (the bombardment rate) $f$. Each particle collides against the collector and returns to the conveyor for the recovery of the enthalpy loss, and the process is repeated. Thus, several hundred impacts can be obtained by recycling a moderate number of particles.

The collector has a flat surface (initially polished to a surface roughness of $0.05 \mu \mathrm{m}$ ) and has a very small mass $\left(4 \times 10^{-4} \mathrm{~kg}\right)$, which allows for the detection of 
a small amount of heat addition (through the temperature rise). In order to minimize the conductive heat losses, the collector is mounted on a very low thermal conductivity substrate $\left(k \approx 0.3 \mathrm{~W} \mathrm{~m}^{-1} \mathrm{~K}^{-1}\right.$ ) made of phenol-formaldehyde (phenolic). Conductive heat losses can be minimized by using a small area of contact between the collector and the substrate. However, the contact area must be large enough to give adequate rigidity to the collector support (for reasons to be discussed in Section 4.2.1). A reference collector is also positioned next to the collector. By observing the temporal temperature variation in the reference collector, we can detect the parasitic heat transfer (e.g. change in the room temperature, the radiation heat transfer).

When the power to the electric heater is turned on, the temperature of the entire chamber increases (by conduction and radiation). After several hours the chamber reaches an equilibrium state, although significant temperature variations exist within it. The flow of the heated particles disturbs the equilibrium and the temperatures of various parts of the chamber will increase. Before starting the actual bombardment of the collector, a deffector (Fig. 1) is placed above it in order to avoid impact. The role of the deflector is to allow the different parts of the system to attain new equilibrium states while the heated spheres are flowing (without any impact with the collector). After this new equilibrium is reached, the deflector is removed and the particles are allowed to strike the collector. This procedure ensures that the increase of the collector temperature is solely due to the conductive and radiative heat transfer during impacts.

\subsection{Measurement of heat transfer during impact}

2.2.1. Calibration. If the bombardment rate, $f$, and the heat transferred per impact, $Q$, are constant and there are no heat losses, the temperature of the collector during the bombardment will vary linearly with time, being given by

$$
T_{2}(t)=T_{2}(0)+\left(\frac{f Q}{m_{2} c_{2}}\right) t
$$

However, in experiments the collector temperature does not follow equation (1). This is due to the presence of heat losses by conduction (through the contact area between the base of the collector and the phenolic support) and also heat transfer by radiation. The result is an initial non-linear rise in the collector temperature followed by a constant temperature asymptote (Fig. 2(a)). When the asymptotic behavior is approached, the impact heat transfer to the collector is balanced by the outgoing conductive and radiative heat transfer. Because of the difficulty in estimating the thermal contact resistance between the collector and the phenolic support and due to the uncertainties in the estimations of the surface emissivities, the analysis of this transient heat transfer problem is not addressed here. Instead, the system is calibrated by (a)

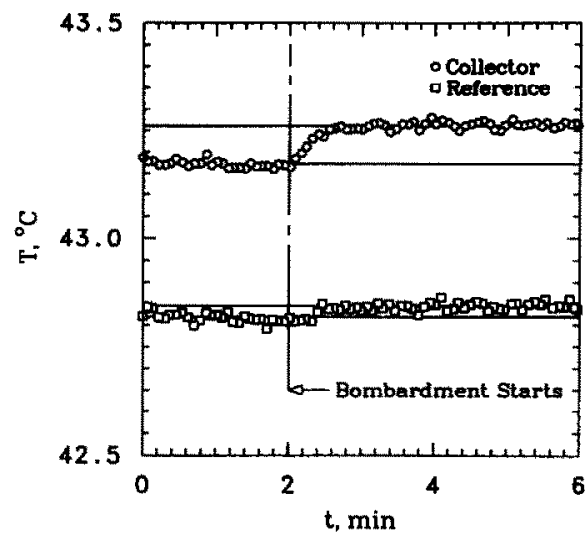

(b)

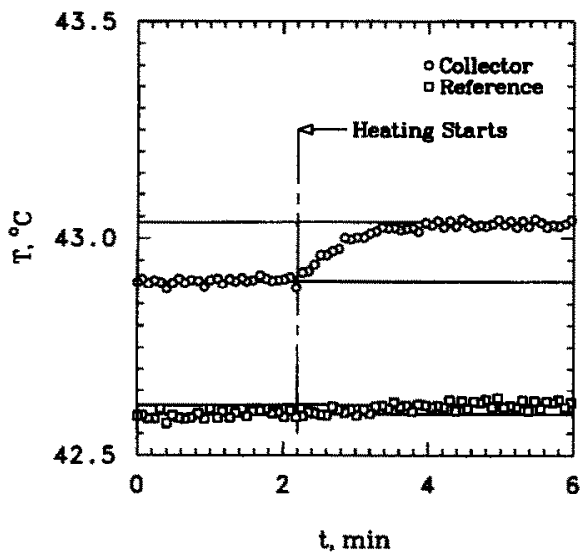

(c)

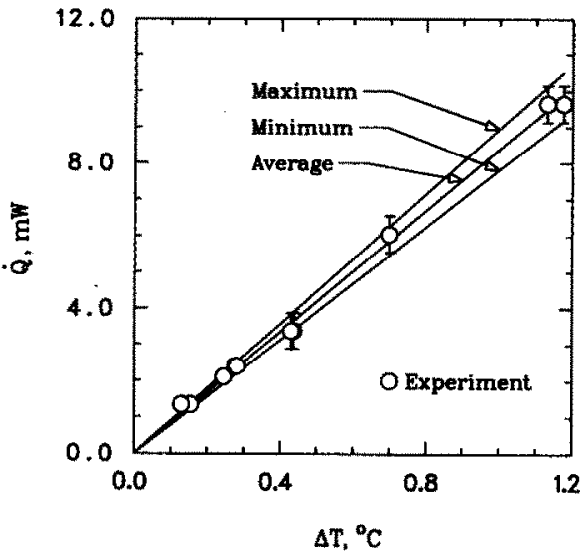

Fig. 2. (a) The temperature of the collector and the reference collector versus time during bombardment. (b) A typical curve obtained during the calibration experiment. (c) A typical calibration curve giving $\dot{Q}$ as a function of the increase in the collector temperature $\Delta T$.

heating the collector at a constant and known rate $\dot{Q}$ using a helium-neon laser.

The rate $\dot{Q}$ can be controlled by placing a combination of filters between the laser source and the collector. The transparency of the filters has been 
determined experimentally with an accuracy of $1 \%$. The calibration is performed at the same temperature and pressure in the chamber as those occurring in the bombardment experiment. To make sure that the collector is absorbing all the incident radiation, at very thin layer of black oxide or black enamel $\left(\varepsilon_{n}=0.96\right.$ 0.98 ) is deposited on the surface (for calibration only). The collector temperature rises with time and then reaches an asymptote (Fig. 2 (b)) and these rises in the collector temperature $\Delta T$ and the heating rate $\dot{Q}$ arc recorded. In order to have an accurate measurement of the heating rate input, two different radiometers are used and the deviations are used to estimate the uncertainty in the measured $\dot{Q}$. A calibration curve is obtained by finding the best linear fit to the experimental data of $\Delta T$ versus $\dot{Q}$ (Fig. 2(c)), i.e.

$$
\dot{Q}=\gamma T \text {. }
$$

2.2.2. Measurement of heat transfer per impact. The amount of heat being transferred per impact $Q$ is determined by measuring $\Delta T$. Then, from the measured bombardment rate $f$ and by using equation (2). the heat transferred per impact is found from

$$
Q=\frac{\dot{Q}}{f}=\gamma \frac{\Delta T}{f}
$$

Note that $Q$ is due to both conduction through the contact area and radiation (during approach, contact and departure of particles).

2.2.3. Radiative heat transfer. To minimize the radiative heat transfer, highly polished surfaces are used (roughness $\approx 0.05 \mu \mathrm{m}$ ). It is also important to note that the peak energy emitted is in the infrared where the emissivities are expected to be very low. However, depending on the radiative properties of the surfaces. the amount of energy exchange between the surface of the particle and the collector can become important. The view factor $F_{1-2}$ between a coaxial sphere and a disk is given in Siegel and Howell [13]. We need to consider three different phases of the impact, namely the free fall phase of the ball, the phase when the ball is in contact with the collector, and the rebound phase.

To estimate $Q_{\text {R.c }}$ we need to know the total, hemispherical emissivities. Since the emissivities of most materials are strongly dependent on the properties of the surface (rugosity, contamination, etc.), they were measured experimentally. This was done by irradiating the surfaces with a helium-neon laser, and measuring the incident and reflected powers. Wavelength and temperature corrections were then made as described in ref. [13]. For the highly polished AISI $440 \mathrm{C}$ and 304 stainless steels this gives $\varepsilon \approx 0.15$, and for pure copper $\varepsilon \approx 0.05$. We have made a parametric examination of the ratio of $Q_{\mathrm{R}, c}$ to the heat transfer during elastic impact, i.e. $Q_{\mathrm{R}, \mathrm{c}} / Q_{0}$, as a function of the emissivities. From Fig. 3(a) we note that the radiative heat transfer is strongly dependent on the emissivity of the collector $\left(\delta_{2}\right)$. (a)

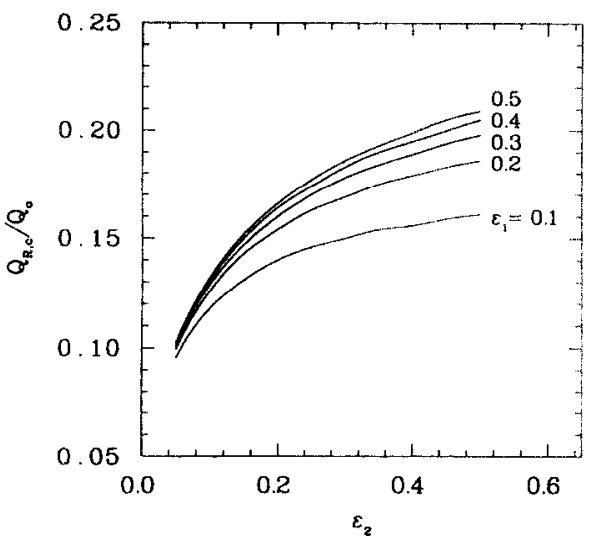

(b)

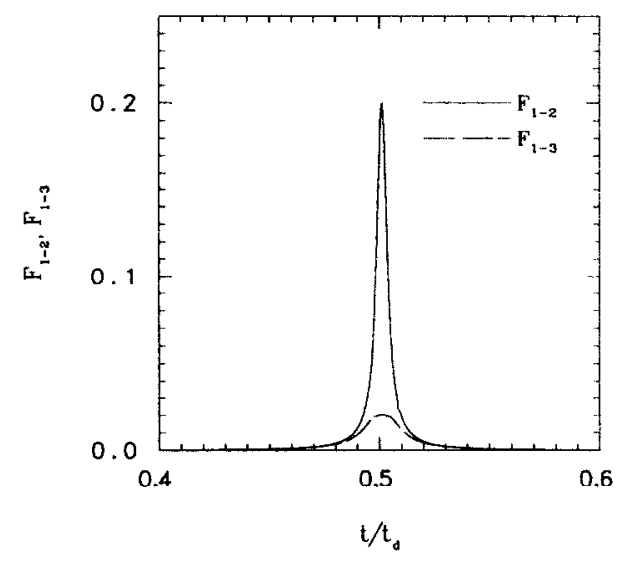

(c)

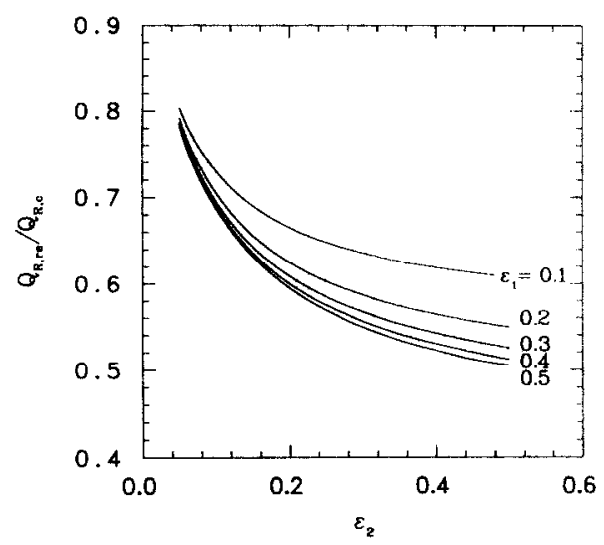

FIG. 3. (a) The ratio $Q_{\mathrm{k}, \mathrm{c}} Q_{v}$ as a function of the emissivities. (b) Change of the view factors $F_{1-2}$ and $F_{1}$, with time; $t_{\mathrm{d}}$ is the total time during which the collector sees the ball. (c) The ratio $Q_{R, r e} / Q_{R, c}$ as a function of the emissivities. The collector and the reference collector are made of the same material.

The radiative heat transfer between the balls and the reference collector $Q_{\mathrm{R}, \mathrm{re}}$ was also determined. The view factor $F_{1-3}$ between the particle and the reference collector is given by Feingold and Gupta [14]. The variations of $F_{12}$ and $F_{13}$ with time (during the free 
fall and rebound) are plotted in Fig. 3(b). The ratio of $Q_{\mathrm{R}, \mathrm{re}}$ to $Q_{\mathrm{R}, \mathrm{c}}$ is plotted in Fig. 3(c). Knowing $Q_{\mathrm{R}, \mathrm{re}}$ and the emissivities $\varepsilon_{1}$ and $\varepsilon_{2}$, we can estimate the radiative heat transfer between the ball and the collector $\left(Q_{\mathrm{R}, \mathrm{c}}\right)$. For the measured emissivities we have $Q_{\mathrm{R}, \mathrm{re}} / Q_{\mathrm{R}, \mathrm{c}}=0.827$ for the copper collector and AISI $440 \mathrm{C}$ particles, and $Q_{\mathrm{R}, \mathrm{re}} / Q_{\mathrm{R}, \mathrm{c}}=0.757$ for the AISI 316 steel collector and AISI $440 \mathrm{C}$ particles. Therefore, the radiative heat transfer $Q_{\text {R.c. }}$ is approximately 1.2 $1.3 Q_{\mathrm{R}, \mathrm{re}}$. From Fig. 3(a) we have $Q_{\mathrm{R}, \mathrm{c}} / Q_{0}=0.13-0.14$ for $\varepsilon_{2}=0.15$.

\section{EXPERIMENTAL RESULTS}

Several experiments were performed where we measured the heat transfer during the impact of $440 \mathrm{C}$ stainless steel balls with a pure copper collector; an AISI 304 stainless steel collector; an AISI 316 stainless steel collector; an AISI O1 tool steel (annealed); and an AISI O1 oil hardened tool steel collector. Both the collector and the reference collector were polished to a surface roughness of $0.05 \mu \mathrm{m}$. All samples were cleaned in acetone and thoroughly washed with ethyl alcohol, and the collector was immediately placed in the evacuated chamber.

\subsection{Copper collectors}

The original design for the collector support was relatively flexible, permitting some transfer of kinetic energy to the collector and hence reducing the total change in momentum of the ball during the impact. A more rigid modified design was then developed for which we anticipate that the contact conditions will be closer to those where the collector is considered as a half-space.

The results are compared in Fig. 4. We note that the more flexible support gives somewhat less heat exchange than the modified design, as we should expect, since the contact time and the maximum area of contact are related to the impulse transmitted to the ball.

However, both sets of results indicate $Q / Q_{0}$ is sub-

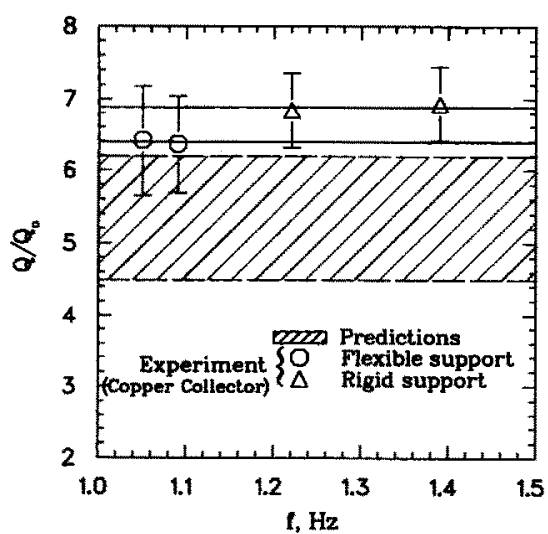

FIG. 4. The normalized measured heat transfer during impact $Q$ versus the bombardment rate $f$ for the copper collector. stantially larger than unity, i.e. more heat is exchanged during impact than is predicted by the elastic theory. This difference is attributed to the plastic deformation induced in the collector by the hard steel balls and indicated by plastic indentations observable in the collector surface at the end of the experiment. These indentations were removed by polishing before the next experiment.

\subsection{Steel collectors}

In order to reduce the plastic deformation, it is necessary to increase the hardness of the collector material. Collectors of AISI 304 and AISI 316 stainless steels were prepared in the same manner as the copper collector, but plastic indentations were again observed after impact. A yet harder collector was therefore machined from AISI O1 tool steel and then hardened to RA 82 by quenching from $800^{\circ} \mathrm{C}$ in warm thin oil. The Rockwell hardness of the tool steel collector hefore quenching was RA 54 and those of the AISI 304, AISI 316 and copper collector were RA 44, RA 43 and RF 63, respectively. To obtain information on the effect of hardness, heat transfer experiments were performed with all these collector materials, including the tool steel collector in both annealed and quenched states. The results of these experiments are described in Section 5.1.

After experiments with the quenched tool steel collector, no permanent indentations could be detected in the collector surface, suggesting that all the impacts are elastic or nearly elastic. With this collector, we also find that the total heat exchange per impact is close to the value predicted by the elastic theory (see Fig. 8).

\section{THEORETICAL PREDICTIONS}

\subsection{Heat exchange during elastic impact}

The analysis of the heat transfer during elastic impact [1] is based on the following principal assumptions. (a) The impact is quasi-static so the Hertzian theory of elastic impact is valid; (b) the impact is perfectly elastic; (c) during the impact, heat is transferred by conduction in the normal direction only; (d) the impact is normal with no spin; (e) the particles make perfect thermal contact; and (f) the surfaces are perfectly smooth.

Under these assumptions, the conductive heat transfer per impact is given by

$$
Q_{0}=0.87 \beta\left[T_{1}(0)-T_{2}(0)\right] A_{0} t_{0}^{1 / 2}
$$

where $A_{0}=\pi a_{0}^{2}$ is the maximum contact area, whose radius is $a_{0}=\left(15 m V^{2} R^{2}\right)^{1 / 5} /(16 E)^{1 / 5}, t_{0}=2.943 a_{0}^{2} /$ $(R V)$ is the duration of the impact, $\beta=\beta_{1} \beta_{2} /$ $\left(\beta_{1}+\beta_{2}\right)$ is an equivalent thermal property (see Nomenclature), $m=m_{1} m_{2} /\left(m_{1}+m_{2}\right)$ is the equivalent mass, $R^{-1}=R_{1}^{-1}+R_{2}^{-1}$ is the relative curvature, $V$ is the relative velocity of impact, and $E=\left[\left(1-v_{1}^{2}\right)\right]$ $\left.E_{1}+\left(1-v_{2}^{2}\right) / E_{2}\right]^{-1}$ is the equivalent Young's modulus. Note that in our case, $m_{2}=\infty$ and $R_{2}=\infty$, 
Table 1. Thermophysical properties of selected materials

\begin{tabular}{lccccccc}
\hline \multicolumn{1}{c}{ Material } & $\begin{array}{c}E \\
\left(\mathrm{~N} \mathrm{~m}^{-2} \times 10^{10}\right)\end{array}$ & $v$ & $\left(\mathrm{~kg} \mathrm{~m}^{-3} \times 10^{3}\right)$ & $\begin{array}{c}c \\
\left(\mathrm{~J} \mathrm{~K}^{-1} \mathrm{~kg}^{-1}\right)\end{array}$ & $\begin{array}{c}k \\
\left(\mathrm{~W} \mathrm{~m}^{-1} \mathrm{~K}^{-1}\right)\end{array}$ & Hardness & $\begin{array}{c}V_{y} \\
\left(\mathrm{~m} \mathrm{~s}^{-1}\right)\end{array}$ \\
\hline SS 440C & 20.0 & 0.30 & 7.6 & 460 & 24.2 & RA 82 & 0.95 \\
SS 316 & 19.3 & 0.30 & 8.00 & 500 & 16.2 & RA 42 & $0.31 \times 10^{-2}$ \\
SS 304 & 19.3 & 0.30 & 8.00 & 502 & 16.2 & RA 44 & $0.40 \times 10^{2}$ \\
O1 (Hardened) & 20.6 & 0.30 & 7.85 & 460 & 24.2 & RA 82 & 0.95 \\
O1 (Annealed) & 20.6 & 0.30 & 7.85 & 460 & 24.2 & RA 54 & $0.15 \times 10^{-1}$ \\
Copper & 11.7 & 0.35 & 8.93 & 385 & 401 & RA 63 & $0.31 \times 10^{-3}$ \\
Glass & 6.9 & 0.17 & 2.50 & 800 & 1.4 & $\cdots$ & $\cdots$ \\
Phenolics & 6.9 & 0.17 & 1.40 & $\cdots$ & & 0.30 &
\end{tabular}

since the collector is assumed to be an infinite elastic half-space. The amount of heat transferred per impact is very small $\left(1-3 \times 10^{-4} \mathrm{~J}\right.$, based on properties from Table 1), and the internal energy of the collector will change only slightly during the experiments. In fact calibration experiments show that the increase in the collector temperature $T_{2}$ is less than $1.5^{\circ} \mathrm{C}$. Initially $\left[T_{1}(0)-T_{2}(0)\right] \geqslant 100^{\circ} \mathrm{C}$, thus $\left[T_{1}(0)-T_{2}(0)\right]$ can be laken constant in equation (4) with an error of less than $1.5 \%$.

Sun and Chen used a correction factor $C_{r}$ to account for the heat conduction in the radial direction, i.e. to relax assumption (c) above. The total conductive heat transfer $Q$ is then given by

$$
Q=C_{r} Q_{0}
$$

The correction factor $C_{r}$ is a constant larger than unity, depending on the Fourier number $F o=\alpha t_{0} / a_{0}^{2}$ (based on the material with lower $\beta$ ) and on the ratios $\lambda^{*}$ and $\mu^{*}$. For AISI $440 \mathrm{C}$ steel balls striking a steel elastic half-space $F o \approx 2 \times 10^{-3}$, the ratios $\lambda^{*}$ and $\mu^{*}$ are close to unity and $C_{r} \approx 1$. The radial heat conduction might be important for larger values of $\lambda^{*}$ and lower values of $\mu^{*}$, especially if $F o$ is greater than about 0.1 .

\subsection{Analysis for non-ideal conditions}

Since many of the assumptions on which Sun and Chen have based their analysis are not satisfied in practical situations, we examine a more realistic model that considers the effect of some of the non-ideal conditions listed in Section 4.1.

4.2.1. Effect of flexibility of support. If the duration of impact is very small, elasto-dynamic effects must be taken into account. Tsai solved this problem by adding wave-effect integrals to the Herizian contact stresses (which are derived for a quasi-static contact). For the impact to be considered quasi-static, the time constant $\tau$ of the system must be short compared to the period $t_{0}$ of the force impulse applied to the system. Hunter (see Johnson [15]) used an approach where he regarded the half-space as an elastic spring in parallel with a dashpot (also known as the Kelvin-Voigt model). The dashpot accounts for the energy dissipated through the half-space by the wave motion. Since the duration of the impact is short, the energy dissipated by the dashpot will be small and the dynamic response will be mainly dominated by the spring. In our experiments, for the case of the impact of a hard steel ball with a steel collector, we have $\tau / t_{0} \approx 2 \times 10^{-6}$, and hence the impact can be considered quasi-static. For more flexible collector supports multiple impacts can occur, but estimates show that the stiffness of the collector support will not have any influence on the heat transfer during elastic impact if it is larger than $1.3 \times 10^{10} \mathrm{~N} \mathrm{~m}^{-1}$, which is the case in this experiment.

4.2.2. Heat transfer during elasto-plastic impact. For the impact to be purely elastic, the velocity of the particles must be less than [15]

$$
V_{Y}=10.342\left(\frac{R^{3} Y_{d}^{5}}{m E^{4}}\right)^{1 ; 2}
$$

For the impact of a spherical, rigid particle with a half-space, equation ( 6 ) reduces to

$$
V_{\gamma}=5.053\left(\frac{Y_{\mathrm{d}}}{E}\right)^{5 / 2}\left(\frac{E}{\rho_{1}}\right)^{1 / 2}
$$

where $Y_{\mathrm{d}}$ is the tensile or compressive dynamic yield stress of the half-space, whose value is close to the static yield stress which in turn is closely related to the hardness. For copper, the maximum velocity for the impact to be completely elastic is $3 \times 10^{-4} \mathrm{~m} \mathrm{~s}^{-1}$, while for steels it ranges from $3 \times 10^{-2} \mathrm{~m} \mathrm{~s}^{-1}$ for an annealed steel of hardness RA 43 to $1 \mathrm{~m} \mathrm{~s}^{-1}$ for a hardened stecl of RA 82. These values are lower than the velocities occurring in the experiment (about $2.3 \mathrm{~m} \mathrm{~s}^{-1}$ ). Typical particle properties in fluidized beds are presented in Table 2 [16].

To estimate the heat transferred during elasto-plastic impact, we consider the impact to be quasi-static and assume that during the engagement phase the material of the collector strain-hardens according to a uniaxial true stress $(\sigma)$-true strain $(\epsilon)$ relation of the type

$$
\sigma=b \epsilon^{n}
$$

where $b$ and $n$ are constants of the collector material. The Tabor empirical equations for the true stress and true strain are 
Table 2. Typical particle properties in fluidized beds

\begin{tabular}{|c|c|c|c|c|c|}
\hline Material & $\begin{array}{c}\text { Mean } \\
\text { diameter } \\
d_{\mathrm{m}}(\mathrm{mm})\end{array}$ & $\begin{array}{c}\text { Density } \\
\rho_{\mathrm{s}}\left(\mathrm{kg} \mathrm{m}^{-3}\right)\end{array}$ & $\begin{array}{c}\text { Pressure } \\
\text { (atm) }\end{array}$ & $\begin{array}{c}\text { Minimum } \\
\text { fluidization } \\
\text { velocity } \\
V_{\mathrm{mf}}\left(\mathrm{m} \mathrm{s}^{-1}\right)\end{array}$ & $\begin{array}{c}\text { Terminal } \\
\text { velocity } \\
V_{\mathrm{t}}\left(\mathrm{m} \mathrm{s}^{-1}\right)\end{array}$ \\
\hline Soda lime glass & 0.650 & 2480 & $\begin{array}{r}1 \\
5 \\
10\end{array}$ & $\begin{array}{l}0.31 \\
0.21 \\
0.16\end{array}$ & $\begin{array}{l}4.60 \\
2.78 \\
1.97\end{array}$ \\
\hline Crown barium glass & 2.600 & 2920 & $\begin{array}{r}1 \\
5 \\
10\end{array}$ & $\begin{array}{l}1.34 \\
0.63 \\
0.45\end{array}$ & $\begin{array}{r}13.47 \\
6.02 \\
4.25\end{array}$ \\
\hline Silica sand & 2.700 & 2630 & 1 & 1.33 & 13.3 \\
\hline
\end{tabular}

$$
\sigma=\frac{p_{\mathrm{d}}}{c}, \quad \epsilon=\frac{a}{5 R}
$$

where $p_{\mathrm{d}}$ is the mean contact pressure and $c$ is a constant close to 3 . The value of $n$ describes the strainhardening ability of the material. In general $0 \leqslant n \leqslant 0.5$. A perfectly plastic material would have a value $n=0$.

During the plastic engagement phase, if the edges of the impression neither pile-up nor sink-in, the contact radius $a$ and the compression $\delta$ are related by the equation

$$
\delta=\frac{a^{2}}{2 R}
$$

Using equations (8)-(10) the contact force $P$ is given by

$$
P=\eta \delta^{(n+2) / 2}
$$

where

$$
\eta=\frac{\pi 2^{n} b c}{5^{n}(2 R)^{n / 2-1}}
$$

The equivalent radius $R=R_{1}$ during the engagement phase. This will not be the case during the elastic recovery phase, since the half-space acquires a permanent concave curvature, defined by a negative value of $R_{2}=-\varrho$.

The impact problem is investigated by writing the momentum equation for the hall. Using equation (11), we get the following equation for the compression $\delta$ :

$$
m_{1} \frac{\mathrm{d}^{2} \delta}{\mathrm{d} t^{2}}+\eta \delta^{(n+2) / 2}=0
$$

Solving this equation, we find the maximum compression $\delta_{\mathrm{p}}$, the duration of the engagement $t_{\mathrm{p}}$, the maximum contact radius $a_{\max }$ and the maximum force $P_{\text {max }}$ are given by

$$
\begin{gathered}
\delta_{\mathrm{p}}=\left[\frac{(n+4) m_{1} V_{1}^{2}}{4 \eta}\right]^{2 /(n+4)}, \quad t_{\mathrm{p}}=\frac{\delta_{\mathrm{p}}}{V_{1}} f(n), \\
a_{\max }=\left(2 R_{1} \delta_{\mathrm{p}}\right)^{1 / 2} \\
P_{\max }=\eta \delta_{\mathrm{p}}^{(n+2) / 2}
\end{gathered}
$$

where

$$
f(n)=\int_{0}^{1} \frac{\mathrm{d} x}{\left(1-x^{(n+4) / 2}\right)^{1 / 2}} .
$$

Note that for $0 \leqslant n \leqslant 1$

$$
1.471 \leqslant f(n) \leqslant \frac{\pi}{2} \approx 1.571 .
$$

The rebound is then taken to be elastic, and the contact radius $a$ and the compression $\delta$ are related by the equation

$$
\delta=\frac{a^{2}}{R}, \quad R^{-1}=R_{1}^{-1}-\varrho^{-1}
$$

The initial radius of the contact area is taken equal to the contact radius $a_{\max }$ occurring at the end of the plastic indentation, i.e.

$$
a_{\max }=\left(2 R_{1} \delta_{\mathrm{p}}\right)^{1 / 2}=\left(R \delta_{\mathrm{e}}\right)^{1 / 2}
$$

where $\delta_{\mathrm{e}}$ is the elastic recovery. For the elastic rebound the compressive force $P$ is given by the Hertzian relation

$$
P=\frac{4}{3} E R^{1 / 2} \delta^{3 / 2}
$$

The momentum equation for the motion of the ball during elastic deformation can be written as

$$
m_{1} \frac{\mathrm{d}^{2} \delta}{\mathrm{d} t^{2}}+\frac{4}{3} E R^{1 / 2} \delta^{3 / 2}=0
$$

Using equations (15), (19) and (20) we can find the elastic recovery $\delta_{\mathrm{e}}$

$$
\delta_{\mathrm{e}}=0.53 \frac{\eta}{R_{\mathrm{I}}^{1 / 2} E} \delta_{\mathrm{p}}^{(n+1) / 2} .
$$

Multiplying equation (21) by $\mathrm{d} \delta / \mathrm{d} t$ and integrating by parts we then find the rebound velocity $V_{2}$ and the rebound duration $t_{\mathrm{e}}$ to be

$$
V_{2}=\left(\frac{16 E R^{1 / 2} \delta_{\mathrm{e}}^{5 / 2}}{15 m_{1}}\right)^{1 / 2}, \quad t_{\mathrm{e}}=1.471 \frac{\delta_{\mathrm{e}}}{V_{2}}
$$

We find that the contact radius $a$ can be approximated by the expressions

$$
a(t)=a_{\max }\left[\sin \pi\left(t / 2 t_{\mathrm{p}}\right)\right]^{1 / 2}, \quad 0 \leqslant t \leqslant t_{\mathrm{p}}
$$




$$
a(t)=a_{\max }\left[\cos \pi\left(\frac{t-t_{\mathrm{p}}}{2 t_{\mathrm{c}}}\right)\right]^{1 / 2}, \quad t_{\mathrm{p}} \leqslant t \leqslant t_{\mathrm{p}}+t_{\mathrm{c}}
$$

for the engagement and the rebound phases respectively (see Fig. 5). These approximations permit a simplified expression to be obtained for the total heat transfer $Q$ with a maximum error of about $1 \%$.

The total heat transfer per unit contact area is a function of the local duration of contact $t$. (which is a function of $a$ ). Then the total amount of heat transferred per impact $Q$ is given by

$$
Q=\int_{0}^{a_{\text {nix }}} \int_{0}^{r_{(}(t)} q \mathrm{~d} t 2 \pi a \mathrm{~d} a
$$

where $q$ is the instantaneous, one-dimensional, conductive heat flux at the interface, and is given by [17]

$$
q=\frac{\beta\left[T_{1}(0)-T_{2}(0)\right]}{(\pi t)^{1 / 2}}
$$

As defined, $t_{\mathrm{c}}(a)$ is the time during which the bodies are in contact over an area of radius $\geqslant a$ and is given by (see Fig. 5)

$$
t_{\mathrm{c}}(a)=t_{1}+t_{2}
$$

Using equations (24) and (25) we find

$$
t_{\mathrm{c}}(a)=\frac{2}{\pi}\left(t_{\mathrm{p}}+t_{\mathrm{e}}\right)\left[\frac{\pi}{2}-\sin \left(\frac{a}{a_{\max }}\right)^{2}\right] .
$$

Then, from (26), (27) and (29), we obtain

$$
\begin{aligned}
Q=8^{1 / 2} \beta\left[T_{1}(0)-\right. & \left.T_{2}(0)\right] a_{\operatorname{mix}}^{2}\left(t_{\mathrm{p}}+t_{\mathrm{c}}\right)^{1 / 2} \\
& \times \int_{0}^{1}\left(\frac{\pi}{2}-\sin ^{-1} x\right)^{1 / 2} \mathrm{~d} x .
\end{aligned}
$$

The last integral is a dimensionless constant, which can be evaluated to give

$$
Q=0.880 \beta\left[T_{1}(0)-T_{2}(0)\right] A_{\text {max }}\left(t_{\mathrm{p}}+t_{\mathrm{c}}\right)^{1_{i 2}}
$$

where $A_{\max }=\pi a_{\max }^{2}$ is the maximum contact area.

The above results can be normalized with respect to the corresponding elastic values, with the result

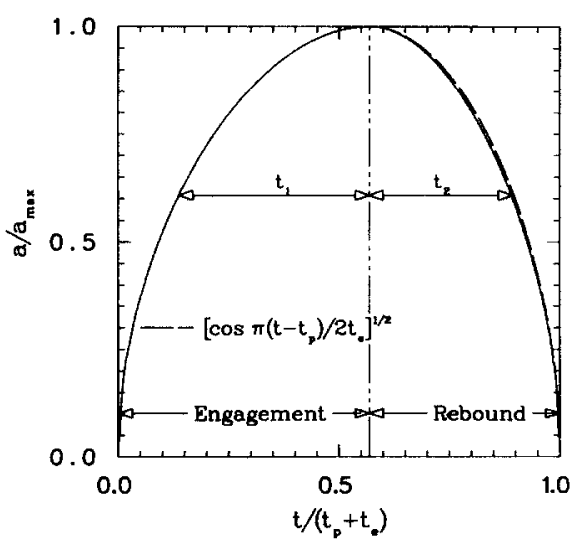

FIG. 5. Change of the contact radius $a$ with time.

$$
\begin{gathered}
\frac{\delta_{\mathrm{p}}}{\delta_{0}}=0.289\left[5^{n}(n+4)\right]^{2(n+4)} D_{1}^{2(1 \ldots n) 5(n+4)} D_{2}^{2(n+4)} \\
\frac{t_{\mathrm{p}}}{t_{0}}=0.340 f(n){ }_{\delta_{0}}^{\delta_{1}}
\end{gathered}
$$

$$
\begin{aligned}
& \frac{\delta_{\mathrm{e}}}{\dot{\delta}_{0}}=0.9095^{-3 n_{i}(4+n)}(n+4)^{(1+n) ;(4+n)} D_{1}^{3(n-1) / 5(n++)} \\
& \times D_{2}{ }^{3(n+4)} \cdot \quad t_{0}=\frac{1}{2 e} \delta_{0}
\end{aligned}
$$

$$
\begin{gathered}
e=\frac{V_{2}}{V_{1}}=\pi^{1 / 2} 5^{-(3 n+2)(n+4)}(n+4)^{i 1,2 n(2 n+3)(n+4)} \\
\times D_{1}^{(n-1)(2(n+4))} D_{2}{ }^{5 i 2(n+4)} \cdot \quad \frac{a_{\mathrm{max}}}{a_{0}}=\left(2 \frac{\delta_{\mathrm{p}}}{\delta_{0}}\right)^{1,2} \\
\frac{Q}{Q_{0}}=2 \frac{\delta_{\mathrm{p}}}{\delta_{0}}\left(\frac{t_{\mathrm{p}}}{t_{0}}+\frac{l_{0}}{t_{0}}\right)^{\prime}
\end{gathered}
$$

where

$$
D_{1}=\rho_{1} V_{1}^{2} / E, \quad D_{2}=2 E_{1}(3 b c)
$$

are dimensionless parameters.

For the particular case where the collector material does not work-harden (such as lead), the engagement phase is fully plastic and the mean contact pressure is constant $\left(p_{\mathrm{d}} \approx 3 Y\right)$, we have

$$
n=0, \quad b \approx Y, \quad c \approx 3 .
$$

Substituting these values into equations (32)-(34) we obtain

$$
\begin{aligned}
& \frac{\delta_{\mathrm{p}}}{\delta_{0}}=0.377 B^{1,5}, \quad \frac{t_{\mathrm{p}}}{t_{0}}=0.201 B^{1 / 9} \\
& \frac{\delta_{\mathrm{c}}}{\dot{\delta}_{0}}=2.440 B^{3110}, \quad \frac{t_{\mathrm{c}}}{t_{0}}-0.537 \mathrm{~B}^{1.20} \\
& e=\frac{V_{2}}{V_{1}}=2.275 B^{1: 4}, \quad \frac{a_{\max }}{a_{0}}-0.868 B^{1: 10}
\end{aligned}
$$

where

$$
B=\frac{V_{1}}{V_{Y}}
$$

The total heat transfer per impact is then

$$
\frac{Q}{Q_{0}}=2 \delta_{\delta_{0}}^{\delta_{p}}\left(\begin{array}{l}
t_{\mathrm{p}} \\
t_{0}
\end{array}+\frac{t_{\mathrm{c}}}{t_{0}}\right)^{1 / 2}=\left(0.305 B^{7 / 20}+0.114 B^{3 / 5}\right)^{1: 2 .} .
$$

During plastic impact, additional heat is generated due to the internal, mechanical energy dissipation. Experiments were performed where the collector was bombarded with balls at the same temperature as the collector. No significant temperature changes were observed in the collector, indicating that this effect can be neglected.

4.2.3. Oblique impact and particle spin. In our experiments, the collector is tilted at an angle of 5 to the horizontal. This is necessary to ensure that the 
particles do not strike the collector after rebound. The friction at the interface can be important if the local angle of incidence $\phi$ is large. $\phi$ is measured between the direction of the velocity of the contact point and the normal to the surface of the collector. As long as some part of the contact area is in a state of adhesion, the slip displacements at other points will be small and frictional heating will be negligible. However, if the whole contact area slips, frictional heating might be significant. This state is known as gross slip. Maw et al. defined two dimensionless parameters $\Phi_{1}$ and $\chi$

$$
\Phi_{1}=\frac{2(1-v)}{\mu(2-v)} \sin \phi, \quad \chi=\frac{(1-v)\left(1+1 / K^{2}\right)}{2-v}
$$

where $K=\left[I /\left(m_{1} R_{1}^{2}\right)\right]^{1 / 2}$ is the radius of gyration of the particle and $I$ is the moment of inertia of the particle about its center of mass. They showed that the whole impact will take place in gross slip if

$$
\Phi_{1} \geqslant 4 \chi-1
$$

while for $\Phi_{1}<1$ there is only a very short period of gross slip at the end of the rebound phase. For the case of a homogeneous steel sphere $(y=0.3), \chi=1.44$ and these conditions correspond to

$$
\sin \phi>5.78 \mu, \quad \sin \phi<1.25 \mu
$$

respectively.

Taking the coefficient of friction $\mu \approx 0.1$ we find that gross slip will be insignificant if $\phi<7^{\circ}$ which will be the case if the balls fall vertically without rotation. If rotation occurs as a result of contact with the side of the release tube, the local angle of incidence will contain an additional term. However, this term will generally be small since no increase in rotational speed can occur during the free fall phase. We therefore conclude that frictional heating will be insignificant in the present experiments.

\section{RESULTS AND DISCUSSION}

The measured and predicted amounts of heat transfer during the elasto-plastic impact of steel balls with a copper collector are shown in Fig. 4. The results show that the heat transferred per impact is six to seven times larger than that predicted by the Hertzian theory of elastic impact. This is attributed to the large plastic deformations occurring in the collector during the impact. The shaded area defines the values predicted by the analysis of Scetion 4.2.2 for $Y-10000$ $14000 \mathrm{psi}$. Since the predicted heat transferred is strongly dependent on the value of the yield stress $Y$, the uncertainties in the measured $Y$ should be reduced as much as possible. The yield stress was therefore estimated from hardness measurements on the collector surface. We note that equation (42) is for fully plastic impact and this ideal behavior is not present in our experiments. Therefore, it is not expected that equation (42) will predict our experimental results accurately. Also note that the particles do not collide

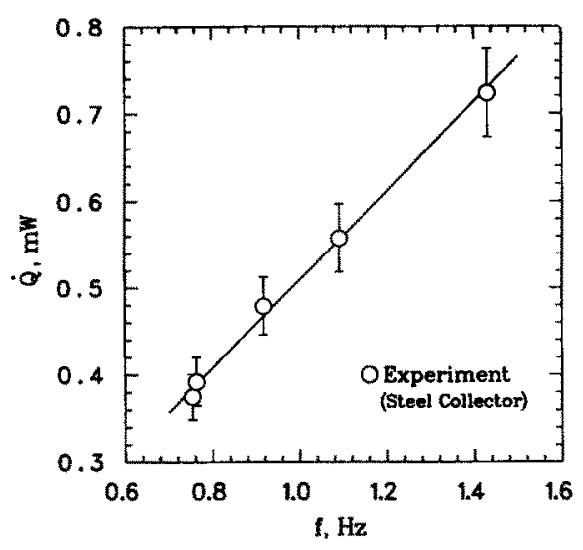

F1G. 6. The measured rate of heat transfer during impact $\dot{Q}$ versus the bombardment rate $f$ for the AISI 304 collector.

with the same area in every impact. There is a statistical distribution to the collision centers (which depends on the apparatus). In principle, this uncertainty in the collision location can be combined with a superposition of indentations to result in an estimate of the multiple-plastic impacts. However, this is beyond the scope of the present work.

Figure 6 shows the effect of impact frequency, $f$, with the AISI 304 stainless steel collector. The measured total rate of heat transfer $\dot{Q}$ varies linearly with $f$ (Fig. 6) as predicted by equation (3). Experiments were also performed with different ball temperatures $T_{1}(0)$ to verify the expected linear dependence of heat transfer rate upon $\left[T_{1}(0)-T_{2}(0)\right]$. The results are given in Fig. 7 for the AISI 316 steel collector.

\subsection{Effect of yield stress}

The experimental results show that the heat transfer during impact is strongly dependent on the hardness of the collector which is closely related to the yield stress $Y$. This behavior is evident from Fig. 8 where the ratio of measured heat transfer $(Q)$ to the predicted heat transfer during elastic impact $\left(Q_{0}\right)$ is plotted against the parameter $B$. This parameter can be interpreted as a measure of the severity of the impact,

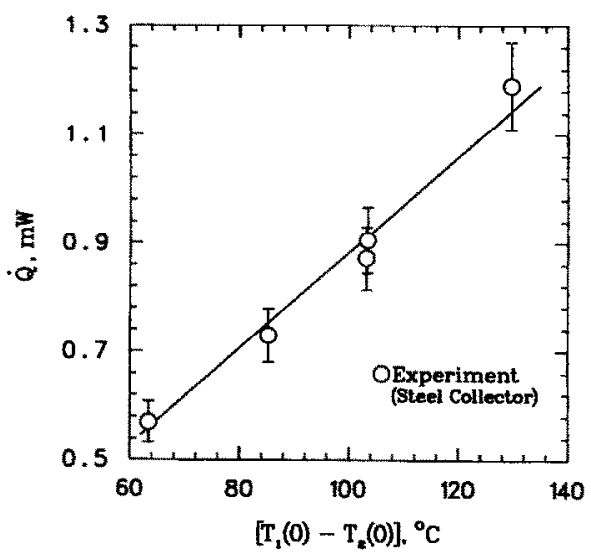

Fig. 7. The measured rate of heat transfer during impact $\dot{Q}$ versus the initial temperature difference $\left[T_{1}(0)-T_{2}(0)\right]$. 


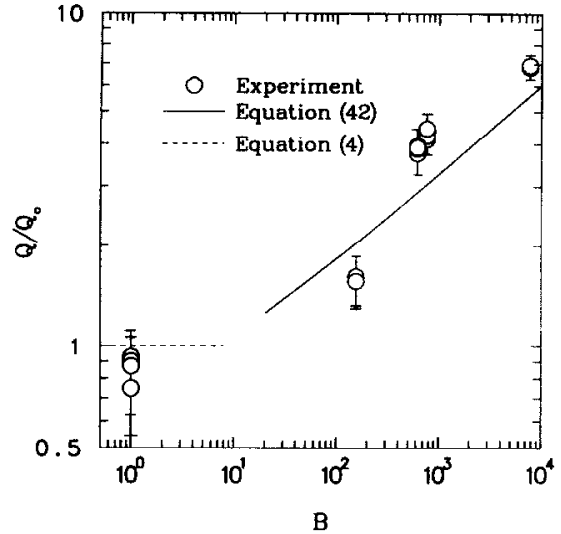

Fig. 8. The normalized measured heat transfer during impact $Q$ versus the parameter $B=V_{1} / V_{Y}$ compared with the predictions of the fully plastic analysis.

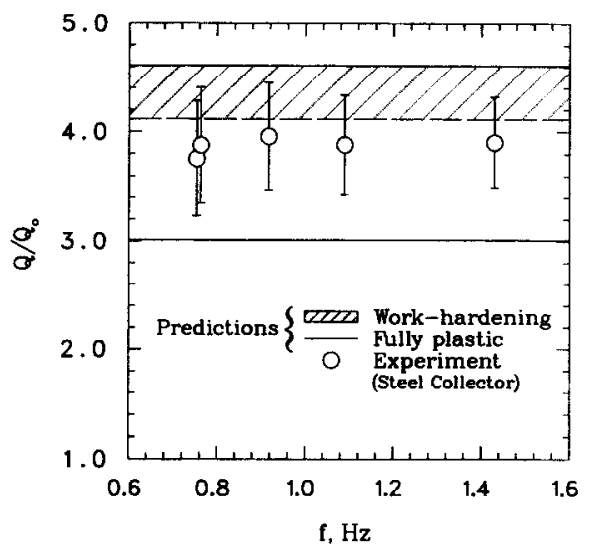

Fig. 9. The normalized measured heat transfer during impact $Q$ for the AISI 304 stainless steel collector compared with the prediction of equation (35).

since it is the ratio between the actual velocity of impact $\left(V_{1}\right)$ and the minimum velocity required to produce plastic dcformations $\left(V_{Y}\right)$, defined by equation (7).

The results with all five collector materials are given in Fig. 8 and they show a progressive increase in the ratio $Q / Q_{0}$ as $B$ is increased. The elastic analysis gives a good prediction of the heat transfer only for the hardest collector.

The solid line in Fig. 8 is obtained from equation (42) and hence corresponds to the case of perfect plasticity without work hardening (i.e. $n=0$ ). It is clear from the figure that this simplification gives a good estimate of $Q / Q_{0}$ for $B>10$, i.e. for large velocities of impact or soft collector materials, where the impact can reasonably be assumed fully plastic.

However, equation (42) does not tend to the expected limit of elastic impact as $B \rightarrow 1$, since the stress-strain law (8) reduces to a step function and contains no elastic or quasi-elastic range when $n=0$.

Better theoretical predictions can be obtained by using the work-hardening theory summarized by equation (35), i.e. by relaxing the assumption $n=0$. Figure 9 compares experimental results and theor- etical predictions for the AISI 304 stainless steel collector, based on the values $c=3.16, b=60 \mathrm{~kg} \mathrm{~mm}{ }^{2}$. and $n=0.40 .45$. The lower limit of the shaded area is obtained for $n=0.4$ and the upper limit for $n=0.45$. The fully plastic prediction $(n=0)$ is also provided for comparison.

\subsection{Effect of radiative heat exchange}

During the laser heating calibration experiments, the observed temporal variation in the temperature of the reference collector is similar to that for the collector, both reaching asymptotic values after an initial transient period during which the temperature rises (Fig. 2(b)). The temperature rise of the reference collector is due to heat conduction from the collector through the support. During the bombardment, radiative heat transfer occurs from the balls to both the collector and the reference collector. In our experiments, for the case of a copper collector, the measured heat transfer per impact is six to seven times larger than that predicted by the elastic impact theory. For the measured emissivities $\left(\varepsilon_{1}=0.15, \varepsilon_{2}=0.05\right)$ and using the results given in Fig. 3(a) the radiative heat transfer represents less than $2 \%$ of the total heat transferred per impact. For the case of a steel collector $\left(\delta_{2}=0.15\right)$, it is less than $7 \%$. Therefore, the radiative heat transfer during impact can generally be neglected in the present experiments.

\section{CONCLUSIONS}

We measured the heat transfer during impact of heated, spherical particles with small, planar collectors. In the experiments, the effect of convection is eliminated by conducting the experiments in an evacuated chamber. The heat losses due to radiation are minimized by using highly reflective surfaces. Radiative heat transfer between the ball and the collector is negligible compared to the heat transfer due to conduction, and can thus be neglected. Highly polished surfaces are used in order to minimize the contact resistance between the ball and the collector. Conductive heat loss from the collector is minimized by using a low thermal conductivity support. The measured heat transfer is larger than that predicted by the Hertzian theory of elastic impact. This is due to the plastic deformation induced in the surface of the collector. A close relationship exists between the hardness of the collector and the measured heat transfer during impact, i.e. the harder the collector material the less is the deviation (copper, stainless steel, and hardened steel collectors are used) from the elastic impact. Our analysis of plastic impact leads to predictions which are in good agreement with the experimental results. Equation (42) allows for a quick estimate of the heat transferred once the hardness, and hence the yield stress of the collector, is known. This conclusion is important because the hardness test is easily performed. We note that accurate measurements of the work-hardening parameters $(n, c, b)$ are 
needed in order to have better estimates of the heat transfer using equation (35). Without these accurate estimates the predictions can be unrealistic. These parameters can be determined from a tensile test performed at a constant strain-rate. For the case of hard steel collectors bombarded with hard steel balls, all impacts appear to be elastic and, within the experimental uncertainties, the measured heat transfer is in good agreement with the predictions from equation (4).

Acknowledgement-The authors are pleased to acknowledge the financial support of the National Science Foundation through grant number CBT-88-14368.

\section{REFERENCES}

1. J. Sun and M. M. Chen, A theoretical analysis of heat transfer due to particle impact, Int. J. Heat Mass Transfer 31, 969-975 (1988).

2. C. H. Mok and J. Duffy, The dynamic stress-strain relation of metals as determined from impact tests with a hard ball, Int. J. Mech. Sci. 7, 355-371 (1965).

3. C. Hardy, C. N. Baronet and V. Tordion, The elastoplastic indentation of a half-space by a rigid sphere, Int . J. Numer. Meth. Engng 3, 451-462 (1971).

4. C. H. Lee, S. Masaki and S. Kobayashi, Analysis of ball indentation, Int. J. Mech. Sci. 14, 417-426 (1972).

5. P. S. Follansbee and G. B. Sinclair, Quasi-static normal indentation of an elasto-plastic half-space by a rigid sphere-I, Int. J. Solids Structures 20, 81-91 (1984).
6. D. Tabor, The Hardness of Metals. Clarendon Press, Oxford (1951).

7. D. G. Rickberry and N. H. Macmillan, On the oblique impact of a rigid sphere against a rigid-plastic solid, Int. J. Mech. Sci. 22, 491-494 (1980).

8. I. M. Hutchings, N. H. Macmillan and D. G. Rickberry, Further studies of the oblique impact of a hard sphere against a ductile solid, Int. J. Mech. Sci. 23, 639-646 (1981).

9. N. Maw, J. R. Barber and J. N. Fawcett, The oblique impact of elastic spheres, Wear 38, 101-114 (1976).

10. N. Maw, J. R. Barber and J. N. Fawcett, The role of elastic tangential compliance in oblique impact, $J . L u b$. Tech. 103, 74-80 (1981).

11. Y. M. Tsai, Dynamic contact stresses produced by the impact of an axisymmetrical projectile on an elastic halfspace, Int. J. Solids Structures 7, 543-558 (1971).

12. J. R. Barber, Adhesive contact during the oblique impact of elastic spheres, J. Appl. Math. Phys. 30, 468-476 (1979).

13. R. Siegel and J. R. Howell, Thermal Radiation Heat Transfer. McGraw-Hill, New York (1981)

14. A. Feingold and K. G. Gupta, New analytical approach to the evaluation of configuration factors in radiation from spheres and infinitely long cylinders, J. Heat Transfer 92, 69-76 (1970).

15. K. L. Johnson, Contact Mechanics. Cambridge University Press, Cambridge (1985).

16. F. W. Staub, R. T. Wood, G. S. Canada and M. H. Mclaughlin, Two-phase flow and heat transfer in fluidized beds, Final Report, prepared for Electric Power Research Institute, research project 525-1 (1980).

17. H. S. Carslaw and J. C. Jaeger, Conduction of Heat in Solids. Clarendon Press, Oxford (1986).

\section{ECHANGE DE CHALEUR DURANT CHOC}

Résumé-La quantité de chaleur échangeé durant le choc d'une particule sphérique avec une surface, depend des propriétés thermophysiques et mécaniques des deux milieus en choc (e.g. rugosité, contamination, état de contrainte, rayon de courbure), la vitesse et la direction du choc, de même, influencent l'échange de chaleur. L'éxistante solution théorique du problème d'échange de chaleur est fondeé sur la theory élastique de Hertz, ou les deux milieus en choc sont considèrés comme deux demi-espaces élastiques. Dans la présente étude, des expériences ont éteés conduites dans le but de mesurer la quantité de chaleur échangeé durant lc choc de particulcs sphériques métalliques avec des collecteurs incrustés dans des substrats ayant de très petit coefficients de conduction thermique. Le transfer de chaleur par convection a èté éliminé en menant les expériences dans une chambre á vide. Cependant, le transfer de chaleur par radiation thermique est présent, et un effort a èté deployé pour le minimiser en utilisant des surfaces hautement réflectrices. Les résultats experimentaux indiquent que la quantité de chaleur échangeé par choc est plus grande que celle prédite par la theory des chocs élastiques de Hertz. Les déformations plastiques induites dans le collecteur dues aux relativement grandes vitesses de choc, resultent en de plus longues dureés de contact et de plus grandes surfaces de contact. On analyse l'échange de chaleur pendant choc plastique et on discute le rôle

d'autres facteurs non-ideaux, tels que la flexibilité du support du collecteur et l'obliquité du choc.

\section{WÄRMETRANSPORT WÄHREND EINES STOSSES}

Zusammenfassung-Die Wärmemenge, die durch Leitung während des Zusammenstoßes eines kugelförmigen Teilchens mit einer Oberfläche transportiert wird, hängt von den thermophysikalischen und mechanischen Eigenschaften der beiden kollidierenden Medien ab. Es gibt weitere Einflußgrößen, wie z.B. die Oberflächeneigenschaften (Rauhigkeit, Verunreinigung, Spannungszustand, Krümmung) sowie Geschwindigkeit und Richtung des Stoßes. Die verfügbaren theoretischen Untersuchungen des Wärmetransports stützen sich auf die Hertz'sche Theorie des elastischen Kontakts, bei dem die beiden zusammenstoßenden Medien wie zwei elastische Halbräume behandelt werden. In der vorliegenden Untersuchung werden nun Experimente vorgestellt, bei denen der Wärmeübcrgang während des Stoßes zwischen metallischen Kugeln und kleinen metallischen Kollektoren, die in einer schlecht leitenden Fläche eingebettet sind, gemessen wird. Konvektion wird dadurch ausgeschlossen, daß das Experiment im Vakuum abläuft. Dennoch gibt es die Strahlungswärmeübertragung, die durch Verwendung stark reflektierender Oberflächen so klein wie möglich gehalten wird. Die Versuchsergebnisse zeigen, daß der bei einem Stoß gemessene Wärmeübergang größer ist also derjenige, den die Hertz'sche Theorie des elastischen Stoßes vorhersagt. Die plastische Deformation, die im Kollektor aufgrund der relativ hohen Stoßgeschwindigkeit auftritt, führt zu einer Vergrößerung der Kontaktfläche und der Stoßdauer. Der zusätzliche Wärmeübergang bei der plastischen Verformung wird analysiert. Abschließend wird die Rolle anderer nichtidealer Bedingungen diskutiert. 


\section{ТЕПЛОПЕРЕНОС ПРИ СОУДАРЕНИИ}

Aнноташия-Количество тепла, переносимого теплопроводностью при соударении сферической частицы с поверхностью, зависит от теплофизических и механических свойств обеих соударяющихся сред. На теплоперенос влияют и такие факторы, как свойства поверхности (т.е. шероховатость, загрязненность, наличие напряжения, радиус кривизны), а также скорость и направление соударения. Обычно теоретическое исследование теплопереноса базируется на теории упругого контакта Герца, рассматривающей соударяющиеся среды как два упрутих полупрострапства. В настоящей работе экспериментально определяется теплоперенос при соударении металлических сферических частиц с металлическимн коллекторами малых размеров прй погружении в подложки с низкой теплопроводностью. Конвективный теплопереное устранялся из-за проведения эксперимента в вакуумной камере. Однако присутствовал радиационный теплоперенос, сводимый к минимуму посредством использования поверхностей с высокой отражательной способностью. Экспериментальные данные показывают, что количество тепла, переносимое в процессе соударения, превышает значение, рассчитанное по теории упругого соударения сред. Плластическая деформация, возникающая в коллекторе за счет относительно высокой скорости соударения, вызывает увеличенис площади контакта и длительности соударения. Анализируется теплоперенос в пронессе пластического соударения и обсуждастся роль других нсидсальных условий, таких как гибкость опоры и непрямое соударение 